\section{O PROBlema do lixo e algumas PERSPECTIVAS PARA REDUÇÃO DE IMPAGTOS}

\author{
Fernanda de Cássia Israel Cardoso \\ Jean Carlos Cardoso
}

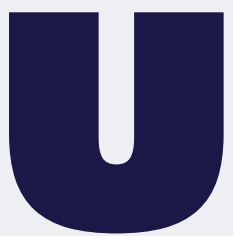

ma das características dos animais é a geração de resíduos. No entanto, os animais em geral produzem resíduos biodegradáveis e de simples decomposição que são utilizados por outros organismos para a transformação da matéria em nutrientes que retornam ao solo e devolvem parte dos nutrientes retirados desse mesmo ambiente, completando um ciclo ecológico importante para a sobrevivência de milhões de espécies.

Da mesma maneira e como outros animais, o ser humano fazia parte desse processo. Porém, algumas mudanças históricas observadas no seu comportamento tornaram os resíduos gerados por humanos um problema ainda não resolvido, sem solução definitiva e que gera grandes impactos ao meio ambiente e à própria sociedade. Dentre as mudanças históricas observadas no ser humano e que desequilibraram o processo de geração de resíduos estão: 1) a passagem de nomadismo para uma condição mais sedentária de sociedade, concentrando também os resíduos produzidos numa área espacial limitada; 2) o aumento exponencial da sociedade humana e sua aglomeração em centros urbanos, limitando o espaço de ocupação com incremento exponencial da geração de resíduos; 3) a descoberta do petróleo como fonte de combustível e outros materiais como o plástico, e a exploração de outros recursos naturais não renováveis como parte do processo de expansão econômica e tecnológica da humanidade, com consumo direto e desenfreado das riquezas naturais não renováveis do planeta; 4) a descoberta do lixo como uma fonte potencial de riscos sanitários e a solução por distanciar os resíduos produzidos nas cidades em lixões, aterros sanitários e similares, colocados em suas áreas marginais e pelo seu despejo em cursos d'água sem o devido ou correto tratamento; 5) o distanciamento da agropecuária (grande utilizadora de recursos naturais) para a produção de alimentos para as áreas urbanas, o que leva a perdas de alimentos no transporte, armazenamento e comercialização desses produtos; 6) a disparidade econômica da atual sociedade, levando ao consumo exagerado e superficial de bens pelos mais ricos, enquanto faltam itens básicos para os mais pobres, o que gera uma grande quantidade de resíduos pela falta da correta distribuição dos recursos; e 7) a diversidade de materiais e produtos gerados pela evolução tecnológica e pelos processos de marketing, a exemplo das embalagens, para diferenciação dos produtos utilizados por essa sociedade.
A TRANSFORMAÇÃO DO LIXO EM RESÍDUOS Considerando o lixo como um problema real para o ambiente, e que ainda é tratado de maneira simplista pela sociedade, que o coloca à distância, é preciso providenciar soluções alternativas para repensar o lixo, como a criação de legislações internacionais. No Brasil, desde sua implementação em 2010, a Política Nacional de Resíduos Sólidos (Lei n¹2.305) tem sido utilizada como base para o gerenciamento dos resíduos, visando a redução na geração, reutilização, reciclagem, tratamento e disposição ambientalmente adequada dos rejeitos gerados.

Dessa forma, considerando a complexidade do lixo produzido e a necessidade de separação dos tipos de resíduos gerados de acordo com sua natureza e quantidade, iremos utilizar a palavra resíduos como forma mais atual de designar todo o tipo de material gerado e inutilizado a partir de um produto ou processo estabelecido. Uma primeira classificação está na separação de resíduos orgânicos e inorgânicos, podendo estes últimos serem ou não recicláveis. Dentre esses resíduos podemos destacar: 1) os resíduos recicláveis, que incluem papéis, plásticos, metais, vidros, entre outros de menor importância em quantidade, permanecendo no ambiente por pouco a até milhares de anos sem serem decompostos; 2) os resíduos orgânicos, que incluem os restos de alimentos, de podas de jardinagem, as fezes, entre muitos outros de origem industrial.

A separação dos resíduos em recicláveis e orgânicos possibilitou a criação de uma nova indústria de reciclados. Esse é o caso das latinhas de alumínio que entram novamente no processo de produção, a partir de processos seguros, com a geração de empregos e renda.

SEPARANDO OS RESÍDUOS FACILITAMOS AS SOLUÇõES Essa ação simples de separação dos resíduos permite uma diminuição considerável na quantidade de lixo descartada diretamente no ambiente sem tratamento. É válido lembrar que essa é uma ação de benefícios mútuos, em que uma cooperativa realiza o serviço de coleta desse lixo para a prefeitura e esta se beneficia da comercialização dos produtos obtidos a partir da coleta. As outras formas de coleta seletiva são a realização pela própria prefeitura do município ou por contratação de empresas particulares.

Dois desafios para esse processo continuam sendo a não separação do reciclável pela população, mesmo havendo coleta seletiva, e o fato de que apenas $18 \%$ das cidades brasileiras dispõem de coleta seletiva. No entanto, o aumento do número de cidades que se engajam no processo foi de $138 \%$ entre 2010 e 2015 . As regiōes Sul e Sudeste concentram $81 \%$ das cidades que dispõe de sistema de coleta seletiva (1).

Existem ainda outros tipos de resíduos de reciclagem mais complexa, como as embalagens de resíduos de agrotóxicos, os medicamentos com data de validade vencida, os materiais que representam riscos biológicos como aqueles provenientes de unidades de saúde e laboratórios de análises clínicas, as pilhas e baterias inutilizadas de aparelhos eletrônicos, os próprios aparelhos eletrônicos como computadores obsoletos, os resíduos da construção civil, as lâmpadas frias do tipo fluorescente, os diferentes tipos de resíduos de 
laboratórios e indústrias, dentre outros. Esses tipos de resíduos têm um destino ou tratamento recomendado por legislação e empresas especializadas na reciclagem desses materiais, mas ainda apresentam dificuldades relativas, sobretudo, ao alto custo do processo.

Nesse sentido, muitas instituições públicas e privadas já possuem equipes que atuam no gerenciamento dos resíduos gerados diretamente na unidade, reduzindo fortemente seus impactos e custos.

\section{RESÍDUOS ORGÂNICOS: UM RESÍDUO FÁCIL E DE POUCO IMPACTO?}

Os resíduos orgânicos podem representar grande risco para a sociedade e ambiente no qual são descartados, principalmente pela alta quantidade, concentração e forma de deposição dos resíduos, que é feita em lixões e aterros sanitários localizados às margens de cidades. Esses métodos não permitem a correta aeração dos resíduos, levando à decomposição anaeróbica (sem a presença de oxigênio) e, portanto, gerando produtos extremamente tóxicos ao ambiente (por exemplo, o gás metano que contribui para o aquecimento global), como o chorume liberado do lixo, que contamina solos e mananciais de água. Esse tipo de resíduo ainda representa um risco para a própria sociedade, para a saúde ou pela reprodução de transmissores de doenças.

Há uma diversidade enorme de tipos de resíduos orgânicos e, portanto, o tratamento separado de alguns resíduos é necessário para que o descarte seja feito de forma a reduzir impactos. Os resíduos orgânicos domésticos representam aproximadamente metade de todo o lixo gerado dentro de casa (restos de alimentos consumidos, podas de jardinagem, óleo usado e as fezes são os principais), sendo que uma família com aproximadamente quatro pessoas gera em média 2 a $7 \mathrm{~kg}$ de lixo orgânico por dia, normalmente descartado in natura no ambiente. Isso é exponencialmente agravado, quando nós, enquanto cidadãos, não separamos os diferentes tipos de lixo ou a prefeitura não oferece a opção de coleta seletiva. Neste caso, os resíduos orgânicos são misturados a outros, aumentando o volume e dificultando a decomposição e a reciclagem, gerando outros subprodutos com maior poder de contaminação ou persistência no ambiente de descarte.

\section{LIXÕES E ATERROS SANITÁRIOS ESTÃO LONGE DA SUSTENTABILI-}

DADE Os lixões e aterros sanitários continuam sendo os principais destinos utilizados pelos municípios para o descarte de resíduos domésticos, orgânicos ou não, "distanciando" o problema do lixo das nossas residências e entorno. A maioria dos lixōes e aterros é posicionada nas áreas marginais das cidades, onde esses resíduos são somente depositados (lixōes), ou formam camadas de lixo e solo (aterros sanitários). Mesmo não sendo a ideal, os aterros sanitários são considerados uma solução melhor que o uso de lixões, sendo que, segundo dados do Banco Mundial, mais da metade do lixo produzido é descartado em aterros sanitários, ao invés de lixōes (2).
Além da saturação com resíduos, prejudicando o meio ambiente, esses locais vivenciam e proporcionam condições sub-humanas para muitos dos chamados catadores de lixos, que coletam parte do material descartado e de valor econômico, em meio a todo o restante do lixo que representa risco a sua própria saúde. De acordo com o Banco Mundial, de todos os 15 milhões de catadores, aproximadamente $75 \%$ trabalham sob condiçôes insalubres, coletando os resíduos diretamente nos lixōes, ao invés de atuar em cooperativas com condiçôes melhores e com direitos trabalhistas mais assegurados (3).

Esse é um impacto de nossas ações irresponsáveis, que se iniciam com a nossa negligência em separar o lixo reciclável daquele não reciclável. Se o lixo fosse separado na fonte por cada cidadão, $90 \%$ deste poderia ser transformado em combustível ou reciclado (4). Além de prejudicar o meio ambiente, ainda geramos uma condição para que essa forma não organizada de trabalho, que envolve trabalho infantil, semiescravidão e outras formas ilegais de uso da mão de obra, se fortaleça, prejudicando inclusive a expansão das cooperativas de catadores nas cidades. Vale lembrar que a cada latinha de cerveja ou refrigerante que descartamos nos cursos d'água ou junto ao lixo orgânico, contribuímos para que o trabalho infantil e de semiescravidão se mantenham ativo nesses locais de descarte.

Nesse contexto, podemos imaginar o quanto os atuais aterros sanitários e lixões ainda geram processos economicamente inviáveis, pois esse tipo de descarte somente gera custos às instituições públicas e cidadãos, ambientalmente incorretos, gerando acúmulo e concentração de grandes quantidades de resíduos, contaminando o solo e a água, e socialmente injustos, criando uma classe marginal de trabalhadores que vivem em condições sub-humanas.

Precisamos de soluções mais consistentes quanto à sustentabilidade do descarte em lixōes e aterros, bem como para o esgoto doméstico que leva fezes e urina diretamente aos cursos d'água. Um exemplo de solução para o esgoto doméstico está no uso dessa água para a irrigação de plantas não comestíveis, como no paisagismo urbano, na floricultura e plantas agrícolas utilizadas para a fabricação de combustíveis como na cana-de-açúcar, visando a produção de álcool combustível, e para a produção de culturas visando a produção de biodiesel. Nos Estados Unidos da América, já existem exemplos de utilização da água de reuso (água proveniente de esgotos urbanos previamente tratados) na irrigação de campos de golfe, jardins e agricultura visando a produção de alimentos (5).

\section{SOLUÇÕES VIÁVEIS PARA OS RESÍDUOS ORGÂNICOS, LIXÕES E ATER-} ROS SANITÁRIOS Uma solução viável para os resíduos orgânicos produzidos em nossas residências é o processo de compostagem aeróbica, que transforma a matéria orgânica em composto, possibilitando a redisponibilização de grande parte dos nutrientes, reduzindo a quantidade de lixo, gerando um produto tecnológico que pode 
ser utilizado como fertilizante em jardins e culturas agrícolas, diminuindo a necessidade de fertilizantes sintéticos e gerando, inclusive, renda para o setor público ou privado. Essas ações e projetos de compostagem podem ser adotados de forma coletiva por prefeituras ou condomínios, ou mesmo individualmente na própria casa.

$\mathrm{O}$ processo de compostagem aeróbica (na presença de $\mathrm{O}_{2}$ ) é preferido em relação ao anaeróbico, atualmente utilizado em lixões e aterros sanitários, pois reduz consideravelmente a emissão de gás metano no ambiente, favorece a recuperação de nutrientes desses resíduos em matéria orgânica e nutrientes que poderão ser utilizados para o cultivo de plantas.

A diferença entre um processo e outro é que no processo aeróbico de compostagem há necessidade de alguns cuidados, como a escolha da mistura de resíduos orgânicos, bem como de outros processos como manutenção da umidade e reviramento periódico das leiras de compostagem, para que somente os microrganismos benéficos se desenvolvam, acelerando o processo de decomposição, sem os odores e acúmulo de animais indesejáveis.

No campus de Araras da Universidade Federal de São Carlos (UFSCar) temos esse processo com resíduos de poda de grama das áreas de jardinagem do campus, com resíduos de alimentos do restaurante universitário ou com esterco bovino proveniente da criação de animais na própria instituição. Da mesma forma, em casa, os resíduos de alimentos vegetais e cascas de ovos podem ser utilizados em mistura com a poda de grama ou de folhas de árvores do jardim como forma de produzir adubo para as plantas (6). Para acelerar o processo e reduzir a necessidade de aplicação constante de água nas composteiras, pode-se utilizar um plástico de cobertura, como o preto, adquirido em lojas de materiais de construção ou outro mais resistente. Em geral, é necessário revirar as leiras e verificar a umidade ao menos uma vez por semana para tornar o processo aeróbico. O composto fica pronto entre 40 e 60 dias, a depender da época do ano e condições da compostagem.

$\mathrm{O}$ mesmo processo pode ser feito em larga escala por empresas particulares, prefeituras ou mesmo em condomínios residenciais ou de forma coletiva por moradores de um bairro. No entanto, isso também requer mudanças em nosso comportamento, sendo necessário que todos contribuam separando o lixo adequadamente para que todo o processo seja beneficiado, sem custos adicionais ou contaminação com resíduos como a presença de papel higiênico em meio à composteira.

O processamento em larga escala pode ser feito com trituradores e maquinários especializados já disponíveis e podem ser utilizados por prefeituras e empresas particulares para fabricação de fertilizantes orgânicos ou organo-minerais comerciais. Atualmente, algumas empresas especializadas em compostagem, em parcerias com empresas e restaurantes comerciais, têm realizado esse processo. Outro processo é a transformação de resíduos da indústria alimentícia em subprodutos ou linhas de produtos de aplicação na agricultura.

Entre as soluções caseiras para a compostagem está a chamada vermicompostagem, que se utiliza de minhocas para degradação dos restos de alimentos depositados e produção de húmus a partir desses resíduos. A vantagem do processo é que pode ser feito de maneira artesanal, mantendo uma caixa plástica contendo um pouco de solo e resíduos de grama ou poda de jardins como folhas de árvores ou similares, com a colocação de minhocas dentro dessa caixa. Nesse caso, os resíduos de alimentos são depositados na caixa e as próprias minhocas realizam o processo de decomposição de parte dessa matéria orgânica, transformando-a em húmus que também pode ser utilizado posteriormente nos jardins e no cultivo de plantas. Atenção especial deve ser dada para a colocação preferencial de resíduos vegetais, evitando a colocação de resíduos de carne, por exemplo, que podem propiciar o surgimento de odores, insetos e roedores indesejáveis na residência.

Outro resíduo orgânico produzido nas casas é o óleo utilizado para frituras e outros processos, que geralmente se acumula e é descartado diretamente no ralo, levando a um processo extremamente oneroso de tratamento de água. Nesse caso, o óleo já pode ser reciclado e em diferentes cidades é possível encontrar pontos de coleta do óleo usado, em geral realizado para a fabricação de sabão artesanal ou mesmo industrial.

Além de diminuir a quantidade de resíduos descartada, por meio da compostagem, há que gerar alternativas e soluções para os atuais locais de deposição do lixo, pois esses locais também necessitam de cuidados especiais, como forma de redução dos riscos e impactos ambientais a que essas áreas e arredores já estão submetidos.

FLORESTAS EM LOCAIS DE DESCARTE Uma alternativa para os lixões e aterros, proposta e concretizada no Centro de Ciências Agrárias da UFSCar, localizado em Araras (SP), em especial pela parceria entre a Comissão de Gerenciamento de Resíduos (Gestão 2013-2015), a seção agrícola e a diretoria, foi utilizar um local com descarte sistêmico de resíduos, local similar a um lixão de resíduos orgânicos em uma área para a implantação de um reflorestamento. Para que o processo ocorresse de forma a propiciar conquistas positivas na implantação do reflorestamento, foram necessários alguns procedimentos para uniformizar a área, visto a grande quantidade de resíduos que havia no local.

Isso foi realizado com auxílio de um trator de esteira que auxiliou na distribuição uniforme dos resíduos dentro da área total utilizada para essa finalidade. Após, um trator acoplado com grade pesada foi utilizado como instrumento para misturar esse resíduo orgânico com o solo da própria área, acelerando o processo de decomposição no solo. Isso foi realizado por três vezes, de agosto e setembro, meses em que há poucas chuvas e o solo está menos encharcado, facilitando o trabalho com máquinas. Durante os meses de setembro a janeiro, a área foi mantida em pousio. Em janeiro de 2014 foram escolhidas mudas de diferentes espécies nativas da região, para constituição de reflorestamento. Com auxílio de um sulcador, foram feitas as linhas de plantio, e as mudas foram plantadas. Atualmente, as plantas já se encontram em reprodução, produzindo frutos e sementes, constituindo uma área de reflorestamento de sucesso. 
A implantação de reflorestamentos em lixões ou aterros sanitários pode ser uma alternativa sustentável. Ela possibilita a reativação da vida nesses locais, que preferencialmente poderiam ser constituídas com espécies nativas da região ou bioma de origem, diminuindo o processo de contaminação do ar e da água. O processo faz o aproveitamento dos nutrientes liberados do lixo pelas plantas, evitando a exposição do solo e contaminação de mananciais de água, promove a formação de uma cobertura natural para o solo, além de contribuir para a redução dos impactos gerados pelo aquecimento global, pois parte dos gases do efeito estufa liberados pelo lixo podem ser parcialmente recuperados pelas plantas, que o transformam em energia para a sua própria sobrevivência e manutenção.

Além disso, esses processos permitem a inativação desses locais para outras finalidades como a construção de residências em locais de risco à população. Essa implantação de florestas em locais de descarte do lixo deve ser planejada, sendo realizada parceladamente à medida que um máximo de resíduos é descartado em determinado setor do aterro, mantendo liberado os demais setores ainda em atividade de descarte. Nesse caso o objetivo não seria a inativação desses aterros, visto o caos que poderia trazer às cidades uma ação imediatista, mas sim o reaproveitamento das áreas já saturadas visando o aumento das áreas de florestas no país. No longo prazo, essas áreas poderão servir de parques e de reservas naturais de conservação da biodiversidade local.

\section{RESÍDUOS DE SAÚDE: NECESSIDADE DE GERENCIAMENTO PARA PRO-} CEDER CORRETAMENTE $O$ gerenciamento dos resíduos de saúde constitui-se de uma importante ferramenta de gestão para que o processo de segregação, manejo, acondicionamento e todas as outras etapas envolvidas para que o descarte final aconteça de maneira correta. Sabe-se que os serviços de saúde geram quantidades enormes de resíduos diariamente e de vários tipos. Esses resíduos são classificados em grupos pela Agência Nacional de Vigilância Sanitária (Anvisa) a fim de tornar aplicável o Regulamento Técnico para descarte dos resíduos dos serviços de saúde (7). Esse regulamento tem a função de orientar o gerenciamento correto dos resíduos e de padronizar os processos nos serviços de saúde através da elaboração de um plano de gerenciamento de resíduos que deve ser criado nos serviços de saúde e de conhecimento de todos os profissionais daquele local. Quando tratamos de resíduos provenientes de serviços de saúde, não podemos nos esquecer do risco de contaminação de solo, água, animais, plantas e principalmente de outras pessoas que podem adquirir doenças em contato com esses resíduos.

Os resíduos de saúde são classificados em grupos A, B, C, D e E, de acordo com a Anvisa, e dentro dessas classificações há subclassificações que detalham os tipos de materiais. O grupo A se define como o grupo de resíduos com risco de contaminação biológica, dentre os quais estão os materiais da saúde, de laboratórios, resíduos de clínicas ou hospitais veterinários, que contêm secreções humanas ou de animais, materiais utilizados em procedimentos, peças anatômicas, resíduos de laboratórios, de vacinas, cultura ou estoque de microrganismos e todos os outros resíduos que contenham restos de materiais biológicos. Alguns desses resíduos precisam de tratamento prévio antes de deixar a unidade geradora. Os resíduos do grupo A que são gerados pelo serviço de assistência domiciliar são coletados por agentes de saúde treinados a fim de evitar o contato e exposição de familiares.

No grupo B estão alocados os resíduos que apresentam riscos químicos para a saúde e ao ambiente; no grupo $\mathrm{C}$ estão classificados os resíduos radioativos; no grupo $\mathrm{D}$ os materiais destinados a reciclagem ou reutilização; e, por fim, o grupo E são os materiais perfuro-cortantes. Os materiais perfuro-cortantes são materiais que apresentam resíduos biológicos, porém são classificados em outro grupo devido à importância de um descarte adequado. Esses devem ser descartados em recipiente adequado, rígido, resistente a puncturas e vazamentos, tampados e devem ser descartados na própria unidade geradora, imediatamente após o uso. No grupo E enquadram-se agulhas, cateteres, lâminas de bisturi e outros dispositivos utilizados em procedimentos invasivos da saúde.

Além desses resíduos específicos, os serviços de saúde também geram resíduos comuns, recicláveis e resíduos orgânicos. Dessa forma, percebe-se como é grande a quantidade de resíduos gerados diariamente pela saúde. Pensando em um hospital de grande porte, a geração de resíduos, se não conduzida de maneira adequada, é um problema importante para o ambiente e pessoas que possam ficar expostas.

Neste ponto, chamamos ainda mais a atenção para a questão do descarte correto dos resíduos de saúde. Hoje, como citado acima, temos uma agência que regulariza e supervisiona os processos de saúde, regras institucionais, inúmeras normas e rotinas presentes no dia a dia dos serviços de saúde, entre outras condutas educativas e fiscalizatórias nos serviços. Dessa forma, por que a questão do descarte dos serviços de saúde é um fator impactante e que merece atenção? Será que existe o risco ou são apenas orientações com excesso de cuidado? Observando nesta direção, percebemos que, infelizmente, o descarte incorreto e, por vezes, irresponsável dos resíduos gerados pelos serviços de saúde ainda é frequente. Os entraves para que esse processo ocorra incorretamente são inúmeros e vão desde a falta de orientação dos profissionais de saúde, até falta de insumos para o descarte correto ou mesmo destino final impróprio após o resíduo deixar a unidade geradora. Essa questão é grave e envolve uma rede de profissionais que fazem parte desta engrenagem, facilitando que erros aconteçam e fragilizando o processo.

O descarte dos resíduos inicia-se no próprio serviço de saúde, imediatamente após os procedimentos com o descarte realizado pelos profissionais. Para auxiliar o descarte, temos cores de lixos padronizados e dispositivos próprios para o descarte de perfuro-cortantes, todos regulamentados pela Anvisa. Os próximos profissionais que têm contato com esses materiais são os colaboradores da equipe de higiene. Importante salientar que há um treinamento diferenciado para higiene hospitalar, na qual as equipes são treinadas para o desempenho correto das funções. Os profissionais da higiene retiram 
os resíduos e os transportam para locais específicos onde estes ficam acondicionados até a retirada para o destino final. A retirada dos resíduos até o destino final geralmente é realizada por empresas especializadas, com veículos apropriados e equipe treinada. $\mathrm{O}$ valor cobrado para esse trabalho varia para cada tipo de lixo, devido às diferenças no tratamento final. Dessa forma, as equipes são orientadas que, além da segurança de todo o processo, existe o fator financeiro que também impacta se o material for descartado erroneamente. Suponha que todo o resíduo hospitalar fosse descartado como resíduo infectante. Além do valor a ser pago ser imensamente maior, também teremos o impacto de mais materiais que receberão um tratamento específico, podendo este agredir o meio ambiente. $\mathrm{O}$ processo élongo, mas se realizado de maneira correta, reduz os riscos de contaminação de pessoas e meio ambiente. No entanto, como já citado acima, esse processo ainda é falho e causa muitos problemas.

Os impactos que os resíduos da saúde causam para a população e para o meio ambiente frequentemente viram notícias e nos mostram uma realidade que não gostamos de ver, mas que acontece em nosso país. Como exemplo, trazemos um caso ocorrido em fevereiro de 2016, quando o país se preparava para receber as Olimpíadas e todo o glamour que acompanha este megaevento (8). Este caso mostra uma catadora de lixo que se feriu com uma seringa que estava descartada incorretamente no lixo comum. Ela foi atendida, mas optou por não aderir ao tratamento e nem ao uso dos equipamentos de proteção individual (EPIs). Este fato é lamentável, mas nosso foco aqui é para o descarte incorreto dos resíduos e, como apenas uma seringa descartada erroneamente, pode mudar o curso de vida de uma pessoa, podendo transmitir doenças, infecçóes ou mesmo expondo a pessoa a tratamentos difíceis e acompanhamentos de longa data.

O gerenciamento dos resíduos de saúde é um desafio para os profissionais da saúde e gestores. No entanto, é também um assunto de responsabilidade e mudança de atitude de toda a população. Temos que lembrar e refletir quando estamos em nossas casas e vamos descartar um medicamento vencido ou por materiais utilizados em medicações injetáveis. Qual é a forma correta de fazer o descarte? É importante enfatizar que todo resíduo proveniente de medicamentos, insumos utilizados na saúde, frascos, são resíduos que necessitam de um descarte especial. No caso das residências, o correto é levar medicamentos vencidos, seringas e agulhas utilizadas para que sejam descartados em uma unidade básica de saúde (UBS) do seu bairro. As UBSs estão orientadas e têm essa prática de receber resíduos de saúde gerados nos domicílios para descarte. Já os resíduos dos serviços de saúde enfrentam uma problemática maior para serem descartados corretamente. Ainda não temos uma solução eficiente para acabar ou diminuir a quantidade desses resíduos, até porque a maior deles parte é imprópria para reuso e outros fins. A estratégia é investir em educação, orientação e incitar a responsabilidade de toda a população para que possamos investir em um cenário mais promissor para o descarte de resíduos.
CONCLUSÕES Uma grande parte do problema do lixo ou dos resíduos está na forma como o tratamos nas nossas próprias residências. A simples separação do lixo na fonte pode garantir possibilidades de tratamento, reciclagem e uma redução drástica na quantidade de lixo descartada inadequadamente. Algumas ações de baixo custo, e outras que podem inclusive gerar renda, podem ainda reduzir os impactos atuais causados pelo lixo disponível em lixões e aterros sanitários.

Fernanda de Cássia Israel Cardoso é enfermeira no Departamento de Assuntos Comunitários e Estudantis (DeACE-Ar) da Universidade Federal de São Carlos (UFSCar), com mestrado em enfermagem pela Universidade Estadual Paulista Júlio de Mesquita Filho (Unesp).

Jean Carlos Cardoso é professor na área de horticultura do Departamento de Desenvolvimento Rural da UFSCar, com doutorado na área de biologia na agricultura e ambiente pelo Centro de Energia Nuclear na Agricultura (Cena/USP).

\section{REFERÊNCIAS}

1. Cempre (Compromisso Empresarial para a Reciclagem). "Coleta seletiva ainda é um desafio para o país, aponta Ciclosoft 2016". Cempre Informa, n.147, maio/junho 2016. Disponível em: http://cempre.org. br/cempre-informa/id/70/coleta-seletiva-ainda-e-um-desafio-para-o-pais--aponta-ciclosoft-2016.

2. The World Bank. "Não desperdice, não queira - residuos sólidos no coração do desenvolvimento sustentável". Notícia publicada em 03 de março de 2016. http://www.worldbank.org/pt/news/feature/2016/03/03/waste-not-want-not---solid-waste-at-the-heart-ofsustainable-development

3. The World Bank. "Brasil: a vida depois do lixão". Notícia publicada em 07 de Maio de 2015. Disponível em http://www.worldbank.org/pt/ news/feature/2015/05/07/brasil-reciclaje-basura-vertederos

4. Cempre (Compromisso Empresarial para a Reciclagem). "Desenvolvimento do sistema passa pelo fim dos lixões". Cempre Informa, n.139, janeiro/fevereiro 2015. Disponível em http://cempre.org.br/cempre-informa/id/33/desenvolvimento-do-sistema-passa-pelo-fim-dos-lixoes

5. Bizari, D. R; Cardoso, J. C. Reuse water and urban horticulture: alliance towards more sustainable cities. Horticultura Brasileira v. 34, n. 3, p. 311-317, Sept. 2016.

6. Para mais instruções de como montar a sua composteira ver vídeo disponível em http://g1.globo.com/sp/sao-carlos-regiao/noticia/2015/06/grama-cortada-produz-adubo-ate-50-mais-potente-diz-pesquisa-da-ufscar.html.

7. Disponível em (http://bvsms.saude.gov.br/bvs/saudelegis/anvisa/2004/res0306_07_12_2004.html).

8. Veja a notícia em http://gazetaweb.globo.com/portal/especial. php?c=4939. 